\title{
An avian femur from the Late Cretaceous of Vega Island, Antarctic Peninsula: removing the record of cursorial landbirds from the Mesozoic of Antarctica
}

\author{
Abagael R West ${ }^{\text {Corresp., } 1,2,3}$, Christopher R Torres $^{4}$, Judd A Case ${ }^{5}$, Julia A Clarke ${ }^{4,6}$, Patrick M OConnor ${ }^{7,8}$, Matthew C \\ Lamanna ${ }^{1}$ \\ ${ }^{1}$ Section of Vertebrate Paleontology, Carnegie Museum of Natural History, Pittsburgh, Pennsylvania, United States \\ 2 Section of Mammals, Carnegie Museum of Natural History, Pittsburgh, Pennsylvania, United States \\ 3 Department of Biological Sciences, University of Pittsburgh, Pittsburgh, Pennsylvania, United States \\ 4 Department of Integrative Biology, University of Texas at Austin, Austin, Texas, United States \\ 5 Department of Biology, Eastern Washington University, Cheney, Washington, United States \\ 6 Jackson School of Geosciences, University of Texas at Austin, Austin, Texas, United States \\ 7 Department of Biomedical Sciences, Ohio University Heritage College of Osteopathic Medicine, Athens, Ohio, United States \\ 8 Ohio Center for Ecology and Evolutionary Studies, Ohio University, Athens, Ohio, United States \\ Corresponding Author: Abagael R West \\ Email address: westa@carnegiemnh.org
}

In 2006, a partial avian femur (South Dakota School of Mines and Technology [SDSM] 78247) from the Upper Cretaceous (mid-Maastrichtian) Sandwich Bluff Member of the López de Bertodano Formation of Sandwich Bluff on Vega Island of the northern Antarctic Peninsula was briefly reported as that of a cariamiform - a clade that includes extant and volant South American species and many extinct flightless and cursorial species. Although other authors have since rejected this taxonomic assignment, SDSM 78247 had never been the subject of a detailed description, hindering a definitive assessment of its affinities. Here we provide the first comprehensive description, illustration, and comparative study of this specimen. Comparison of characters that may be assessed in this femur with those of avian taxa scored in published character matrices refutes the inclusion of SDSM 78247 within Cariamiformes, instead supporting its assignment to a new, as-yet unnamed large-bodied species within the genus Vegavis, and therefore its referral to a clade of semiaquatic anseriforms. Important character states diagnostic of Vegavis + Polarornis include strong craniocaudal bowing of the femoral shaft, the presence of a distinct fossa just proximal to the fibular trochlea, and the broad and flat shape of the patellar sulcus. Referral to Vegavis is based on the presence of a distinctive proximocaudal fossa and distolateral scar. This genus was previously known only from $V$. iaai, a smaller-bodied taxon from the same locality and stratigraphic unit. Our reassignment of SDSM 78247 to Vegavis sp. removes the record of cariamiform landbirds 
from the Antarctic Cretaceous. 





25

26

27

28

29

30

31

32

33

34

35

36

37

38

39

40

41

42

43

44

45

46

47

48

49

50

51

52

53

54

55

56

57

58

59

60

61

62

63

64

65

66

67

68

69

70

\section{Abstract}

In 2006, a partial avian femur (South Dakota School of Mines and Technology [SDSM] 78247) from the Upper Cretaceous (mid-Maastrichtian) Sandwich Bluff Member of the López de Bertodano Formation of Sandwich Bluff on Vega Island of the northern Antarctic Peninsula was briefly reported as that of a cariamiform - a clade that includes extant and volant South American species and many extinct flightless and cursorial species. Although other authors have since rejected this taxonomic assignment, SDSM 78247 had never been the subject of a detailed description, hindering a definitive assessment of its affinities. Here we provide the first comprehensive description, illustration, and comparative study of this specimen. Comparison of characters that may be assessed in this femur with those of avian taxa scored in published character matrices refutes the inclusion of SDSM 78247 within Cariamiformes, instead supporting its assignment to a new, as-yet unnamed large-bodied species within the genus Vegavis, and therefore its referral to a clade of semiaquatic anseriforms. Important character states diagnostic of Vegavis + Polarornis include strong craniocaudal bowing of the femoral shaft, the presence of a distinct fossa just proximal to the fibular trochlea, and the broad and flat shape of the patellar sulcus. Referral to Vegavis is based on the presence of a distinctive proximocaudal fossa and distolateral scar. This genus was previously known only from $V$. iaai, a smaller-bodied taxon from the same locality and stratigraphic unit. Our reassignment of SDSM 78247 to Vegavis sp. removes the record of cariamiform landbirds from the Antarctic Cretaceous.

\section{Introduction}

In 2005, an expedition co-directed by one of us (J.A. Case) recovered a partial avian left femur as part of a field investigation of Upper Cretaceous sedimentary units in the James Ross Basin of the northern Antarctic Peninsula (Fig. 1). The femur (SDSM 78247; Figs. 2, 3) was recovered from the Sandwich Bluff locality on the western half of Vega Island. The stratigraphic position of the specimen places it in the lower part of the uppermost Cretaceous (earliest Late Maastrichtian) Sandwich Bluff Member of the López de Bertodano Formation, at a level some 12 meters upsection from the concretionary horizon that yielded the holotype and referred skeletons of the anseriform bird Vegavis iaai (Clarke et al., 2005, 2016).

A preliminary report of SDSM 78247 provisionally identified this femur as that of a terrestrial, cursorial bird belonging to either the otherwise exclusively Cenozoic Phorusrhacidae ('terror birds') or the extant Cariamidae (seriemas) within Cariamiformes (Case et al., 2006). This taxonomic assignment was based on the large size of the femur and three features of its distal morphology: an enlarged and caudally prominent tibiofibular crest, a laterally expansive lateral condyle, and a broad fibular trochlea. Nevertheless, in a review of Antarctic phorusrhacid fossils, Cenizo (2012) questioned this referral and instead identified a number of femoral character states that SDSM 78247 shares with various extant and Mesozoic foot-propelled diving birds (e.g., Hesperornithiformes, Gaviidae, Podicipedidae). These include a strongly curved shaft, a shallow patellar sulcus, a broad distal end with a laterally projecting fibular trochlea, a shallow intercondylar sulcus, a reduced fovea for insertion of the tendon of $\mathrm{m}$. tibialis cranialis, and a long medial supracondylar crest. Subsequently, Agnolín et al. (2017) attributed SDSM 78247 to an indeterminate taxon within Vegaviidae, their newly-proposed clade of Gondwanan neognathous waterbirds that diversified in the Late Cretaceous and allegedly survived into the 
71 Paleocene. Agnolín et al. (2017) regarded SDSM 78247 as a member of Vegaviidae based on a 72 suite of features that the specimen shares with the putative vegaviids Polarornis gregorii and 73 Vegavis iaai. Agnolín et al.'s (2017) referral of several other Cretaceous and Paleogene taxa to 74 Vegaviidae has recently been contested (Mayr et al., 2018). Here we provide the first detailed 75 description and systematic comparison of SDSM 78247.

\section{Institutional Abbreviations}

MACN, Museo Argentino de Ciencias Naturales, Buenos Aires, Argentina; MLP, Museo de La Plata, La Plata, Argentina; SDSM, South Dakota School of Mines and Technology, Rapid City, USA; TMM, Texas Memorial Museum, Austin, USA.

\section{Systematic Paleontology}

Aves Linnaeus, 1758

Galloanserae Sibley, Ahlquist, and Monroe, 1988

Anseriformes Wagler, 1831

Vegavis Clarke, Tambussi, Noriega, Erickson, and Ketcham, 2004

Species indeterminate

Referred Specimen: SDSM 78247, a partial left femur preserved in two pieces.

Locality and Horizon: Locality V2005-3, 'Plesiosaur Papoose,' Sandwich Bluff, Vega Island, Antarctic Peninsula. Lower part ( $\approx$ Unit SBM5 of Roberts et al. [2014]; J.A. Case, pers. obs.) of the Upper Cretaceous (earliest Late Maastrichtian) Sandwich Bluff Member of the López de Bertodano Formation. This location is 6 meters below the baby plesiosaur site of Martin et al. (2007), and about 48 meters below the hadrosaur tooth described by Case et al. (2000). See Roberts et al. (2014) for detailed stratigraphic information on the Sandwich Bluff site.

\section{Description}

SDSM 78247 is a largely complete left femur (Figs. 2, 3) that is preserved in two pieces; both ends are present but the middle portion of the shaft is missing. The proximal piece is $3.2 \mathrm{~cm}$ in length and $1.4 \mathrm{~cm}$ wide across the proximalmost portion of the shaft. The distal piece is $4.7 \mathrm{~cm}$ in length and $2.2 \mathrm{~cm}$ wide across the distal condyles. Though the femoral head and most of the femoral trochanter are not preserved, the latter was probably craniocaudally narrow as estimated from its broken base. On the caudal surface of the proximal fragment, near the proximal end and immediately lateral to the broken base of the femoral head, there is a well-defined, circular proximocaudal fossa (Fig. 3B, D). The insertion of the m. iliotrochantericus takes the form of a prominent quadrangular tubercle on the lateral side of the proximal end of the shaft (Fig. 3A-C). Overall, the proximal fragment of the femur is wider mediolaterally than deep craniocaudally, though these dimensions become progressively more equal distally such that the broken distal end of the proximal fragment is subcircular in cross section. Although a portion of the shaft is missing, the femur was clearly markedly bowed cranially.

The distal portion of SDSM 78247 is laterally compressed (i.e., deeper craniocaudally than wide mediolaterally) and oval in cross section at its broken proximal end. The relative bone 
117 wall thickness (RBT, sensu Smith and Clarke, 2014) is approximately $36 \%$. There is a subtle

118 distolateral scar located on the lateral face of the shaft at the approximate midlength of the distal 119 piece (i.e., roughly three-fourths the estimated length of the femur from its proximal end; Fig. $3 \mathrm{~A}-\mathrm{C})$. At approximately the same proximodistal level, the medial supracondylar crest expands into a massive, proximodistally elongate tuberosity that projects caudally from the remainder of the femoral shaft (Fig. 3B). Distally, there is a broad, shallow patellar sulcus on the cranial surface of the bone, and the region of the intercondylar sulcus is poorly preserved (Fig. 3A, F). The medial condyle is damaged, inhibiting comparisons with the lateral condyle. On the lateral condyle, the fibular trochlea is broad, laterally expansive, and strongly proximally deflected (Fig. $3 \mathrm{~B}, \mathrm{C}, \mathrm{F})$. Its lateral and medial margins are formed by the prominent but slightly weathered fibular and tibiofibular crests, respectively, with a broad, shallow, proximocranially-directed groove occupying the space between these crests (Fig. 3B, C, F). There is a low medial epicondyle proximal to the medial condyle (Fig. 3A, B, D).

\section{Comparisons}

SDSM 78247 and Vegavis iaai share two features that were proposed by Clarke et al. (2016) to differentiate Vegavis from Polarornis. The first of these is the presence of a deep, round ligament scar on the proximocaudal face. The new femur exhibits a condition similar to that of V. iaai: in both, this scar forms a round fossa with a distinct lip around at least the proximolateral margin (Fig. 4I, J). By contrast, this scar is shallow and poorly defined in anatids (e.g., Mergus serrator, Anas platyrhynchos, Anser anser) and absent in screamers (e.g., Chauna torquata) and galliforms (e.g., Gallus gallus, Meleagris gallopavo). The scar is present as a raised structure in other foot-propelled diving taxa such as loons (e.g., Gavia stellata) and grebes (e.g., Aechmophorus occidentalis, Podilymbus podiceps).

The new femur and $V$. iaai also share a elongate scar on the distolateral margin, a feature that is not observed in the holotypic specimen of Polarornis gregorii (Fig. 4A, B, C, E, F, G, I, J, $\mathrm{K})$. A similar distolateral scar has been reported in the distal femur of a partial skeleton from the López de Bertodano Formation of Seymour Island that has been tentatively assigned to Polarornis (Museo de La Plata [MLP] 96-I-6-2; Acosta Hospitaleche and Gelfo, 2015; Agnolín et al., 2017; Mayr et al., 2018); however, this bone is poorly preserved, and we were unable to assess the presence or form of this scar as it was originally figured. The presence, form, and position of this distolateral scar is highly variable across Neognathae. In V. iaai and SDSM 78247, the scar forms a single, low ridge that is positioned near the cranial margin in lateral view and well proximal to the lateral condyle. Among anatids, this scar abuts the lateral condyle near the caudal margin in Anas platyrhynchos and Anser anser; in M. serrator, by contrast, it occupies a position similar to that seen in $V$. iaai but is bipartite, forming two distinct scars. A scar in this location is not observed in screamers (e.g., C. torquata) or galliforms (e.g., G. gallus, $M$. gallopavo). In other foot-propelled diving birds, this scar is present as two widely spaced tubercula either near the caudal margin (in crown-group loons) or near the midline (in grebes). However, a conspicuous raised scar in this location is absent in proposed stem loons (e.g., Colymboides minutus; Storer, 1956).

SDSM 78247 can be easily differentiated from the holotype and referred specimens of $V$. iaai (Clarke et al., 2005, 2016) by several features, including absolute size; the former is nearly twice the size of the femora of the latter two skeletons. Also, in SDSM 78247, the intersection between the lateral margin of the femoral shaft and the articular surface of the fibular trochlea appears abrupt rather than gradational in caudal view. In the new femur, the proximal part of the 
163 trochlea is rotated proximally, generally a notch-like intersection (Worthy et al., 2017:character 164 220) (Fig. 4I). By contrast, in V. iaai, as well as in P. gregorii, the proximal margin of the fibular 165 trochlea grades smoothly into the shaft (Fig. 4J, K). Additionally, the round proximocaudal ligament scar diagnostic of Vegavis is close to the lateral margin in V. iaai (Fig. 4J) but positioned slightly nearer to the midline in SDSM 78247 (Fig. 4I). Furthermore, in V. iaai, the margin of this fossa is encircled by a prominent lip, though this lip is least conspicuous medially. In the new femur, however, only the proximolateral margin of this fossa is bordered by a lip. The raised distolateral scar characteristic of Vegavis is better developed in V. iaai than SDSM 78247 (Fig. 4A, B, E, F, I, J), though this may be due to weathering of the latter. In distal view, the medial condyle of SDSM 78247 appears proportionally slightly smaller relative to the lateral condyle than in V. iaai, however, this area is heavily damaged in SDSM 78247 (Fig. 4Q, R). Also in distal view, the fibular trochlea of SDSM 78247 appears slightly shallower and more proportionally thicker $(\mathrm{RBT} \approx 36 \%)$ than in $V$. iaai $(\mathrm{RBT} \approx 21.6 \%$; Garcia Marsà et al., 2017).

Of the 290 characters in the phylogenetic data matrix of Worthy et al. (2017), 35 pertain to the femur, and 21 of these (i.e., $7 \%$ of the total character set) could be definitively scored in SDSM 78247. SDSM 78247 was scored identically to both V. iaai and P. gregorii for 19 of the 21 femoral characters in the Worthy et al. (2017) matrix that could be assessed in the new fossil. These characters include: (188) a concave antitrochanteric articular face; (193) a lack of pneumatic openings on the caudal face adjacent to the antitrochanteric articular face; (194) the conformation of the obturator impression as a single large scar near the antitrochanteric articular face; (195) a weakly-developed scar for insertion of the medial part of the $\mathrm{m}$. puboischiofemoralis; (198) a weakly-marked impression for the m. iliofemoralis internus; (199) an elongate shaft with subparallel medial and lateral margins; (200) a strongly craniocaudally bowed shaft; (201) a relatively straight medial face in caudal view; (202) the position of the scar for insertion of the m. iliotrochantericus caudalis at mid-craniocaudal depth on the lateral face; (204) the position of the tuberosity of the medial crest at the medial margin of the caudal face; (206) widely separated insertions for the $\mathrm{m}$. obturatorius lateralis and the $\mathrm{m}$. ischiofemoralis; (207) the $\mathrm{m}$. gastrocnemialis lateralis tubercle forms a rugose scar on the lateral face proximocranial to the fibular trochlea; (211) the medial condyle comprises approximately half of the total width across the condyles; (213) the patellar sulcus is broad and flat in cranial view; (214) the presence of a notch for the $\mathrm{m}$. tibialis tendon on the distal end of the lateral condyle; (215) a shallow popliteal fossa; (218) the medial supracondylar crest is short with a notched medial profile; (219) the fibular trochlea and lateral condyle extend equally distally; and (220) the proximal part of the articular surface of the fibular trochlea is rotated cranially, forming a prominence that is markedly offset from the lateral face. Additionally, although the trochanteric crest in SDSM 78247 is missing, it was likely craniocaudally narrow as in V. iaai and $P$. gregorii. Characters from the Worthy et al. (2017) matrix apomorphic for SDSM 78247 are (205) orientation of the lateral condyle in cranial view divergent from axis of the shaft; and (209) the absence or reduction of a distinct depression on the caudal face immediately proximal to the fibular trochlea (see Supplemental File for character scorings).

Although SDSM 78247 was originally assigned to Cariamiformes (Case et al., 2006), it differs markedly from the femora of all members of this clade; for example, no taxon within Cariamiformes possesses the distinct scars discussed above. The new femur also differs from Cariama cristata with respect to 11 of the 21 scorable characters from the Worthy et al. (2017) matrix, including the following states that are present in C. cristata but not in the new specimen: 
209 (194) the conformation of the obturator impression as two scars; (195) the presence of a strongly

210 developed scar for the insertion of the m. puboischiofemoralis pars medialis; (198) the

211 impression for the m. iliofemoralis internus is a well-marked rugosity; (200) a shaft that is

212 straight in lateral view; (207) the presence of the tubercle for the $\mathrm{m}$. gastrocnemialis lateralis as a

213 round scar near the fibular trochlea; (209) the absence of a distinct depression immediately

214 proximal to the caudal articular surface of the fibular trochlea; (211) the medial condyle

215 contributing more than half of the maximum mediolateral width across the condyles; (215) a

216 deep popliteal fossa; (218) the lateral edge of the distal end of the shaft in caudal view is

217 smoothly curving and continuous with the condyle; and (220) the fibular trochlea is caudally

218 directed, merging smoothly into the shaft. Additionally, the circular proximocaudal fossa present

219 in the new femur is absent in both C. cristata (which is convex in this area, lacking any

220 depressions) and phorusrhacids (Alvarenga and Hofling, 2003). The distolateral scar present in

221 SDSM 78247 is also absent in both C. cristata and phorusrhacids (Alvarenga and Hofling,

222 2003). Furthermore, in Cariamiformes, the patellar sulcus is deep and is bordered by sharp crests

223 on the cranial parts of the condyles (Alvarenga and Hofling, 2003). By contrast, in the new

224 femur, the patellar sulcus is shallow and broad.

225

226

227

228

229

230

231

232

233

234

235

236

237

238

239

\section{Discussion}

The morphology of SDSM 78247 is consistent with its membership in Vegavis. This assertion is based on the identical scores of the new femur and $V$. iaai with respect to 19 of the 21 scorable characters from the phylogenetic data matrix of Worthy et al. (2017). SDSM 78247 also exhibits the circular proximocaudal fossa that is synapomorphic of Vegavis, as well as the elongate distolateral scar that is diagnostic of Vegavis but not Polarornis. SDSM 78247 may be differentiated from $V$. iaai based on the one remaining scorable femoral character (the shape of the caudal condyle), as well the overall size of the element and the position and shape of the proximocaudal fossa. These distinctions suggest that the new specimen likely represents a new species of Vegavis; however, this putative new form is, at present, too incompletely represented to warrant formally erecting a new taxon.

Of the four femoral character states proposed by Agnolín et al. (2017) as diagnostic for Vegaviidae that are scorable in SDSM 78247, the new femur is consistent with three: (1)

240 craniocaudal bowing of the shaft; (2) the presence of a distinct fossa just proximal to the fibular trochlea; and (3) a broad and flat shape of the patellar sulcus. SDSM 78247 is inconsistent with the fourth proposed state, the presence of the obturator impressions as two separate, rugose scars. However, V. iaai is also inconsistent with this state (sensu Worthy et al. [2017] but contra Agnolín et al. [2017]). Thus, this conformation of the obturator impressions is likely not diagnostic of Vegavis + Polarornis.

Our reassessment of the partial avian femur SDSM 78247 reveals the presence of a comparatively large-bodied and likely new Vegavis species from the latest Cretaceous of Vega Island, Antarctica, and unambiguously removes the only record of a cursorial bird (specifically Cariamiformes; Case et al., 2006) from the Mesozoic of that continent. Morphological comparisons presented herein ally SDSM 78247 more closely with $V$. iaai than with any other sampled taxon, and as such are consistent with the placement of the specimen within Vegavis. SDSM 78247 is distinguished from $V$. iaai and $P$. gregorii both by morphology and by overall size; the new femur is most similar in size to, though still larger than, that of Polarornis sp. MLP 96-I-6-2 (Acosta Hospitaleche and Gelfo, 2015). 
255

256

257

258

259

260

261

262

263

264

265

266

267

268

269

270

271

272

273

274

275

276

277

278

279

280

281

282

283

284

285

286

287

288

289

290

291

292

293

294

295

296

297

298

299

300

The osteohistology of all previously described Vegavis (MLP 93-I-3-1, MACN-PV 19.748) and Polarornis (TTU P 9265) specimens indicates that these birds had reached adulthood, or nearly so, at the time of death (Chinsamy et al., 1998; Clarke et al., 2005, 2016; Garcia Marsà et al., 2017). As such, the much greater size of SDSM 78247 cannot be easily explained by ontogenetic variability, and instead suggests taxonomic distinction. The new femur exhibits Vegavis-like states of some characters that have been proposed to differentiate that genus from Polarornis (i.e., proximocaudal fossa, distolateral scar; Clarke et al., 2016; Agnolín et al., 2017; Mayr et al., 2018). SDSM 78247 also has a much greater relative bone thickness than $V$. iaai, corresponding more closely to $P$. gregorii (RBT $=37 \%$; Chinsamy et al., 1998 ; de Mendoza and Tambussi, 2015) in this regard, but this may be a consequence of allometric considerations and/or functional scaling in aquatic/diving-specialized taxa. Extensive long bone osteosclerosis such as that observed in SDSM 78247 has been proposed as a correlate of diving specialization, and it scales with positive allometry (e.g., Chinsamy et al., 1998; de Mendoza and Tambussi, 2015). The identification of SDSM 78247 as belonging to a previously unrecognized species within Vegavis substantially increases the known body size range of this taxon.

\section{Conclusions}

Our restudy of the isolated avian femur SDSM 78247 from the Upper Cretaceous López de Bertodano Formation of Antarctica - which was previously attributed to Cariamiformes, constituting the lone Cretaceous record of that clade - demonstrates that the specimen instead pertains to a close relative of the waterbird Vegavis iaai, known from the same locality just down section. SDSM 78247 bears a strong morphological resemblance to the femur of $V$. iaai but is much larger than both this taxon and Polarornis gregorii, which is known from much younger deposits just prior to the K/Pg boundary on nearby Seymour Island. The refutation of SDSM 78247 as a member of Cariamiformes has important paleobiogeographical implications. The geographical connectivity and the timing of exchange between faunas from South America and other parts of the globe during the Mesozoic and Cenozoic remain contentious (e.g., Mayr, 2009). However, this proposed cariamiform record from the Cretaceous of Antarctica - which was formerly the most ancient, globally - no longer requires an explanation. The earliest records of Cariamiformes instead consist of forms from the Paleogene of Europe and a tentatively referred specimen from South America (Mayr, 2009; Mayr et al., 2011).

\section{Acknowledgments}

This research began as one of a series of investigations led by one of us (J.A. Case) in concert with researchers from the Museo de La Plata and the Instituto Antártico Argentino. We thank Dr. James Martin of the School of Geosciences at the University of Louisiana at Lafayette for his collection (on February 18, 2005) and curation of the specimen which has been studied here. We also thank D. Edward Malinzak (Black Hills State University) for locating SDSM 78247 in the SDSM Museum of Geology collections, and Sally Shelton and Darrin Pagnac (SDSM) for loan of the specimen (to M.C.L.). We are grateful to Mary Hennen and John Bates (Field Museum of Natural History) for photographing the femora of Phoebastria nigripes (FMNH 313761) and Macronectes halli (FMNH 339546). We thank Federico Agnolín (MACN) for sharing his original photographs of Polarornis gregorii (TTU P 9265) and providing helpful review comments on the manuscript, and Andrew Farke (Raymond M. Alf Museum of

Peer) reviewing PDF | (2017:12:22371:1:3:NEW 28 May 2019) 
301

302

303

304

305

306

307

308

309

310

311

312

313

314

315

316

317

318

319

320

321

322

323

324

325

326

327

328

329

330

331

332

333

334

335

336

337

338

339

340

341

342

343

344

345

Paleontology) and Gerald Mayr (Senckenberg Research Institute) for additional helpful review comments and advice.

\section{Funding Statement}

Support was provided by the Rea Postdoctoral Fellowship of Carnegie Museum of Natural History (to Abagael R. West) and by the National Science Foundation Office of Polar Programs grants 0003844 (to Judd A. Case), 0087972 (to James Martin), ANT-1142129 (to Matthew C. Lamanna), ANT-1141820 (to Julia A. Clarke), and ANT-1142104 (to Patrick M. O'Connor).

\section{References}

Acosta Hospitaleche C, Gelfo JN. 2015. New Antarctic findings of Upper Cretaceous and lower Eocene loons (Aves: Gaviiformes). Annales de Paléontologie 101:315-324.

Agnolín FL, Brissón Egli F, Chatterjee S, Garcia Marsà JA, Novas FE. 2017. Vegaviidae, a new clade of southern diving birds that survived the K/T boundary. The Science of Nature 104(11-12):87.

Alvarenga HMF, Hofling E. 2003. Systematic revision of the Phorusrhacidae (Aves: Ralliformes). Papéis Avulsos de Zoologia 43:55-91.

Case JA, Martin JE, Chaney DS, Reguero M, Marenssi SA, Santillana SM, Woodburne MO. 2000. The first duck-billed dinosaur (Family Hadrosauridae) from Antarctica. Journal of Vertebrate Paleontology 20:612-614.

Case J, Reguero M, Martin J, Cordes-Person A. 2006. A cursorial bird from the Maastrichtian of Antarctica. Journal of Vertebrate Paleontology 26(3, Supplement):48A.

Cenizo MM. 2012. Review of the putative Phorusrhacidae from the Cretaceous and Paleogene of Antarctica: new records of ratites and pelagornithid birds. Polish Polar Research 33(3): 239-258.

Chinsamy A, Martin LD, Dodson P. 1998. Bone microstructure of the diving Hesperornis and the volant Ichthyornis from the Niobrara Chalk of western Kansas. Cretaceous Research 19:225-235.

Clarke JA, Chatterjee S, Li Z, Riede T, Agnolín F, Goller F, Isasi MP, Martinioni DR, Mussel FJ, Novas FE. 2016. Fossil evidence of the avian vocal organ from the Mesozoic. Nature 538:502-505.

Clarke JA, Tambussi CP, Noriega JI, Erickson GM, Ketcham RA. 2005. Definitive fossil evidence for the extant avian radiation in the Cretaceous. Nature 433:305-308.

de Mendoza R, Tambussi C. 2015. Osteosclerosis in the extinct Cayaoa bruneti (Aves, Anseriformes). Insights on behavior and flightlessness. Ameghiniana 52:305-313.

Garcia Marsà JA, Agnolín FL, Novas F. 2017. Bone microstructure of Vegavis iaai (Aves, Anseriformes) from the Upper Cretaceous of Vega Island, Antarctic Peninsula. Historical Biology:1-5.

Mayr G. 2009. Paleogene Fossil Birds. Springer: Berlin. 262 pp.

Mayr G, Alvarenga H, Clarke JA. 2011. An Elaphrocnemus-like landbird and other avian remains from the late Paleocene of Brazil. Acta Palaeontologica Polonica 56:679-684. 
346

Mayr G, De Pietri VL, Scofield RP, Worthy TH. 2018. On the taxonomic composition and phylogenetic affinities of the recently proposed clade Vegaviidae Agnolín et al., 2017 neornithine birds from the Upper Cretaceous of the Southern Hemisphere. Cretaceous Research 86:178-185.

Roberts EM, Lamanna MC, Clarke JA, Meng J, Gorscak E, Sertich JJW, O'Connor PM, Claeson KM, MacPhee RDE. 2014. Stratigraphy and vertebrate paleoecology of Upper Cretaceous-?lowest Paleogene strata on Vega Island, Antarctica. Palaeogeography, Palaeoclimatology, Palaeoecology 402:55-72.

Smith NA, Clarke JA. 2014. Osteological histology of the Pan-Alcidae (Aves, Charadriiformes): correlates of wing-propelled diving and flightlessness. The Anatomical Record 297:188199.

Storer RW. 1956. The fossil loon, Colymboides minutus. The Condor 58:413-426.

Worthy TH, Mitri M, Handley WD, Lee MS, Anderson A, Sand C. 2016. Osteology supports a stem-galliform affinity for the giant extinct flightless bird Sylviornis neocaledoniae (Sylviornithidae, Galloanseres). PLoS ONE 11(3):e0150871.

Worthy TH, Degrange FJ, Handley WD, Lee MS. 2017. The evolution of giant flightless birds and novel phylogenetic relationships for extinct fowl (Aves, Galloanseres). Royal Society Open Science 4:170975. 
Figure $\mathbf{1}$ (on next page)

Map of Vega Island, Antarctica, modified from Roberts et al. (2014).

Star indicates approximate location of Sandwich Bluff, the site that yielded the avian femur (SDSM 78247) described herein. 


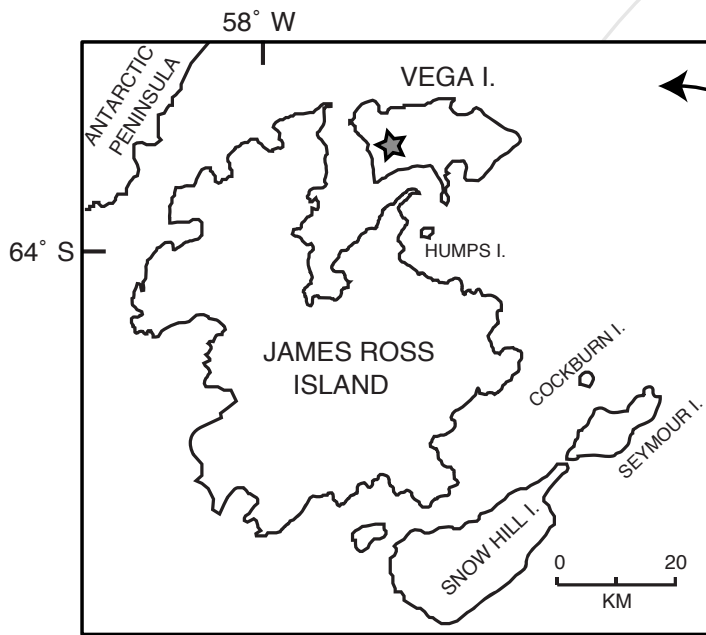


Figure 2

Photographs of left femur of Vegavis sp. (SDSM 78247).

Proximal fragment in (A) cranial, (B) caudal, (C) lateral, (D) medial, and (E) proximal views;

distal fragment in (F) cranial, (G) caudal, (H) lateral, (I) medial, and (J) distal views. Arrows in $E$ and J indicate cranial (top of image) and medial (left side of image) directions. 


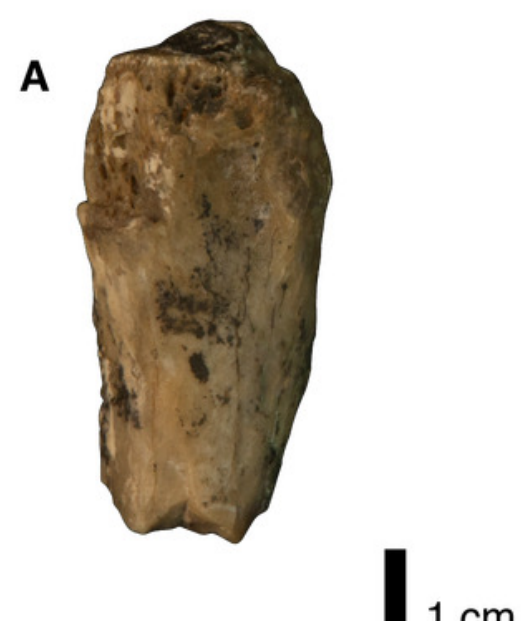

B

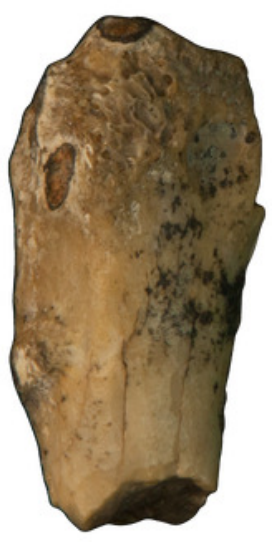

$1 \mathrm{~cm}$

F
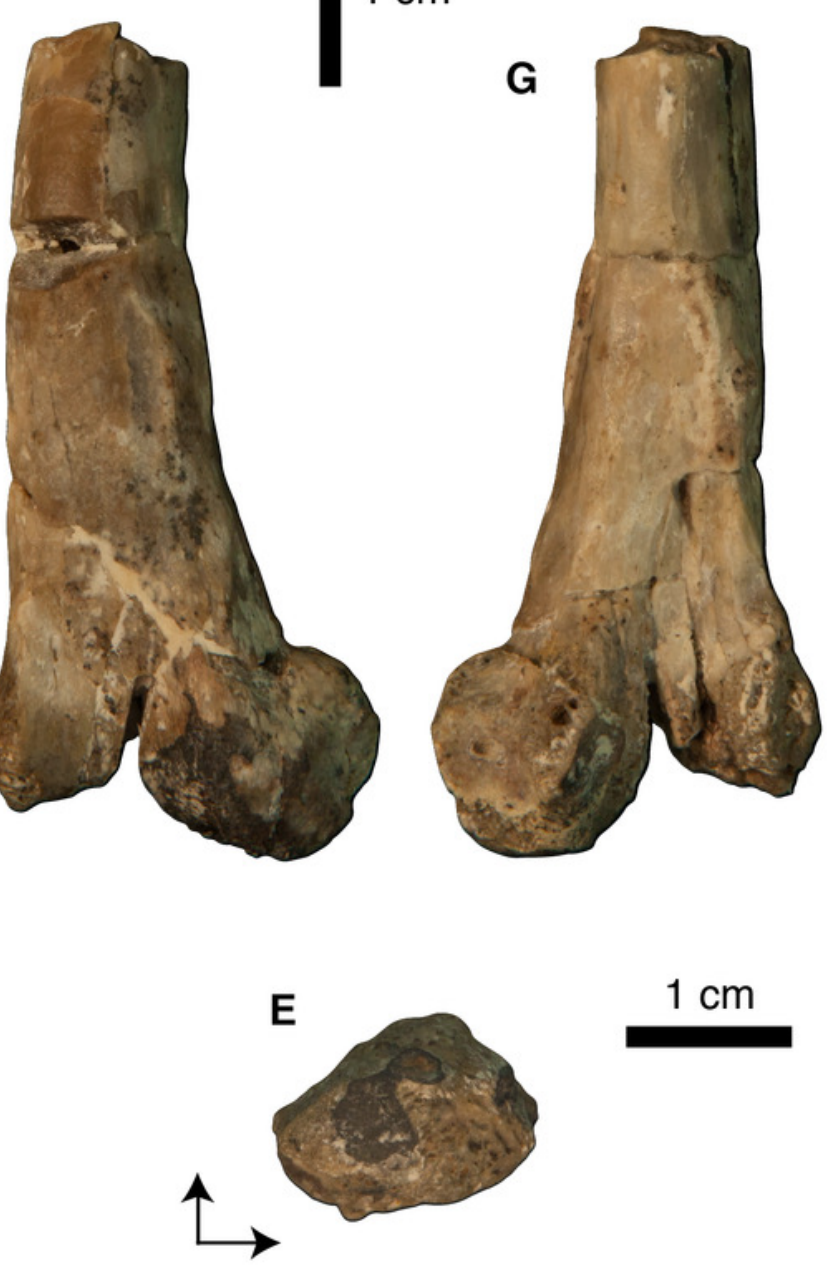

Figure 3 (on next page)

Line drawings of left femur of Vegavis sp. (SDSM 78247).

(A) cranial, (B) caudal, (C) lateral, (D) medial, (E) proximal, and (F) distal views. Arrows in $\mathrm{E}$ and $\mathrm{F}$ indicate cranial (top of image) and medial directions. Hatching indicates worn or broken areas. Abbreviations: af, antitrochanteric face; ds, distolateral scar; fc, fibular crest; $\mathrm{ft}$, fibular trochlea; ftc, fovea for insertion of tendon of $\mathrm{m}$. tibialis cranialis; imi, insertion for m. iliotrochantericus; Ic, lateral condyle; mc, medial condyle; msc, medial supracondylar crest; pf, proximoventral fossa; pop, popliteal fossa; ps, patellar sulcus; tfc, tibiofibular crest; tmg, tubercle for insertion of $\mathrm{m}$. gastrocnemialis. Scale bar $=1 \mathrm{~cm}$. 
$A$

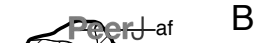

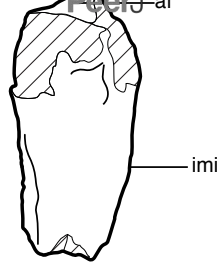
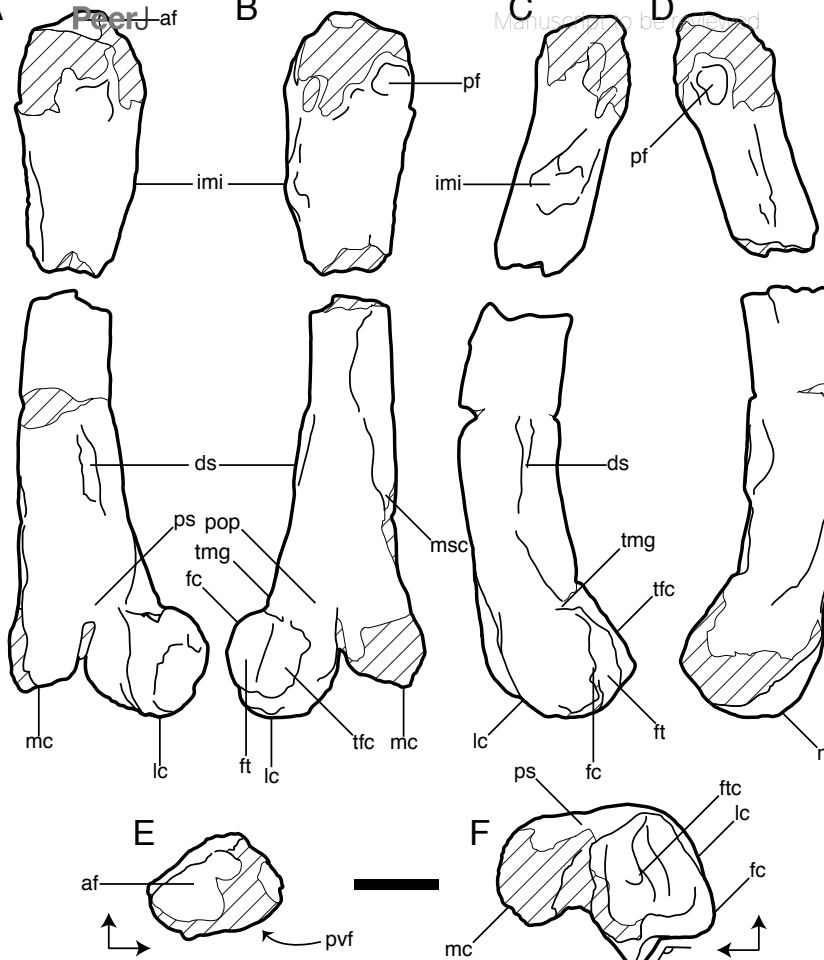

Peer] reviewing PDF | (2017:12:22371:1:3:NEW 28 May 2019)


imi

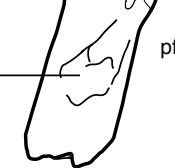




\section{Figure 4}

Comparison of left femora.

$(A, E, I, M, Q)$ Vegavis sp. (SDSM 78247), (B, F, J, N, R) Vegavis iaai (cast of MACN-PV 19.148, reversed), (C, G, K, O, S) Polarornis gregorii (TTU P 9265), and (D, H, L, P, T) Cariama cristata (TMM M-10446), in cranial (A-D), lateral (E-H), caudal (I-L), medial (M-P), and distal (Q-T) views. Abbreviations as in Fig. 3 except: $h$, femoral head; is, intercondylar sulcus; le, lateral epicondyle; me, medial epicondyle; $t$, femoral trochanter. Scale bar $=1 \mathrm{~cm}$. 

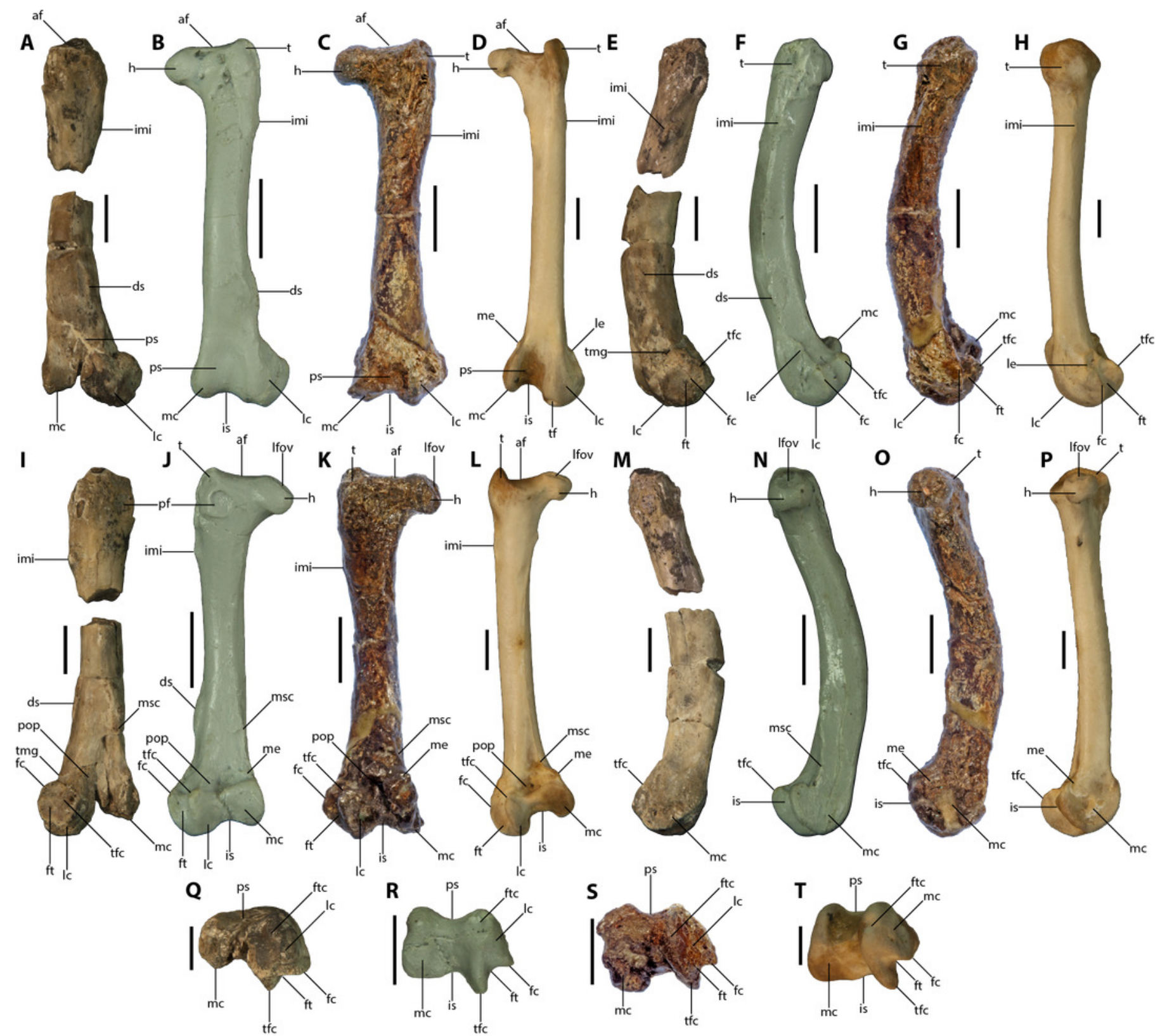